\title{
Covid-19: A year into the pandemic, what has changed from the first, to the second, and the third waves?
}

\author{
Mohammad Sultan, $\mathrm{PhD}^{1}$
}

I. Faculty of Medicine, Dalhousie University

I

$t$ has been over 16 months since the first case of SARS COV 2 was identified in Wuhan, China ${ }^{1}$. Soon after, the virus spread to the rest of the world and was declared a global pandemic ${ }^{2}$. When the virus first hit, many countries were unprepared. Limited knowledge of the virus combined with shortage of specialized equipment and proper personal protective equipment lead to rapid spread of the virus and an influx in hospitalization and death ${ }^{3}$. We started hearing new phrases such as limiting spread and quarantine, and states of emergency were declared all over the world. Many restrictions were put in place to limit spread within and between communities. Scientists and clinicians started conducting research to better understand the disease and target the virus. Hospitals became more familiar and prepared to deal with the new virus and as result developed more efficient treatment plans. Overall, the numbers of new cases/deaths were decreasing, and it looked like we had succeeded in withstanding the pandemic. This initial outbreak would later be known as the first wave.

The second wave started few months later. Despite the notable decrease in the spread over the summer, the second wave was more aggressive, and was associated with a big spike in daily cases and death numbers ${ }^{4}$. Several factors contributed to rapid spread during the second/third waves including public, medical, viral and societal factors. The effect of the first wave was felt by everyone, even those who were not directly infected by the virus. Many people lost their jobs and had to depend on social assistance. This had negative impacts on individual mental health ${ }^{5}$ as well as the economic and financial burden on different governing bodies6. Therefore, when cases were decreasing during the summer, many countries started to ease restrictions and allow in person gatherings. Meanwhile, the virus itself was evolving and new variants were emerging. The new variants were spreading faster, leading to a surge in cases admitted to hospitals and an increased demand for intensive care unit beds ${ }^{7,8}$. Despite the experience gained from dealing with the first wave, hospitals were overwhelmed, and once again we were facing a shortage in resources. Regardless of the early signs and many reports predicting a second wave ${ }^{9}$, lower case numbers coupled with the roll out of the vaccines lead to people becoming negligent and letting their guards down. Despite the period of case decline between the second and third waves, the numerous predominant variants with high attack rates resulted in the spike in daily cases that we are currently seeing.

Several vaccines have been approved in different parts of the world early in the second wave ${ }^{10}$. Some countries achieved faster vaccination rates and as result public and societal measures were relaxed. However, despite the ongoing vaccination efforts it remains unclear how effective the different vaccines are in protecting against the new variants that are emerging ${ }^{11}$. Similarly, the duration of immunity achieved by different vaccines is yet to be established, with reports already suggesting a booster dose might be required for some types $^{12}$. Finally, concerns have emerged recently about potential side effects of some of the approved vaccines, slowing vaccination rates and in turn increasing the potential of being infected by the virus.

Despite the increase in daily cases and the spread of the new variants, health care workers and scientists continue to fight the spread of the virus courageously. It remains to be seen how long this pandemic will persist, however, it is certain that we are better equipped at this stage than when it started. 


\section{References}

1. Lau, H. et al. The positive impact of lockdown in Wuhan on containing the COVID-19 outbreak in China. J. Travel Med. 27, 1-7 (2020).

2. Daniel, S. J. Education and the COVID-19 pandemic. Prospects 49, 91-96 (2020).

3. Kontis, V. et al. Magnitude, demographics and dynamics of the effect of the first wave of the COVID-19 pandemic on allcause mortality in 21 industrialized countries. Nat. Med. 26, 1919-1928 (2020)

4. Cacciapaglia, G., Cot, C. \& Sannino, F. Second wave COVID-19 pandemics in Europe: a temporal playbook. Sci. Rep. 10, 1-8 (2020).

5. Khan, K. S., Mamun, M. A., Griffiths, M. D. \& Ullah, I. The Mental Health Impact of the COVID-19 Pandemic Across Different Cohorts. International Journal of Mental Health and Addiction 1-7 (2020) doi:10.1007/s11469-020-00367-0.

6. Atkeson, A. What Will Be the Economic Impact of COVID-19 in the US? Rough Estimates of Disease Scenarios. http://www. nber.org/papers/w26867.pdf (2020) doi:10.3386/w26867.
7. Duong, D. What's important to know about the new COVID-19 variants? CMAJ : Canadian Medical Association journal = journal de l'Association medicale canadienne vol. 193 E141-E142 (2021).

8. Van Der Made, C. I. et al. Presence of Genetic Variants among Young Men with Severe COVID-19. JAMA - J. Am. Med. Assoc. 324, 663-673 (2020).

9. $\mathrm{Xu}, \mathrm{S} . \& \mathrm{Li}, \mathrm{Y}$. Beware of the second wave of COVID-19. The Lancet vol. 395 1321-1322 (2020).

10. Forni, G. et al. COVID-19 vaccines: where we stand and challenges ahead. Cell Death Differ. 28, 626-639 (2021).

11. Rubin, R. COVID-19 Vaccines vs Variants - Determining How Much Immunity Is Enough. JAMA - J. Am. Med. Assoc. 325, 1241-1243 (2021).

12. Kim, J. H., Marks, F. \& Clemens, J. D. Looking beyond COVID-19 vaccine phase 3 trials. Nat. Med. 27, 205-211 (2021).

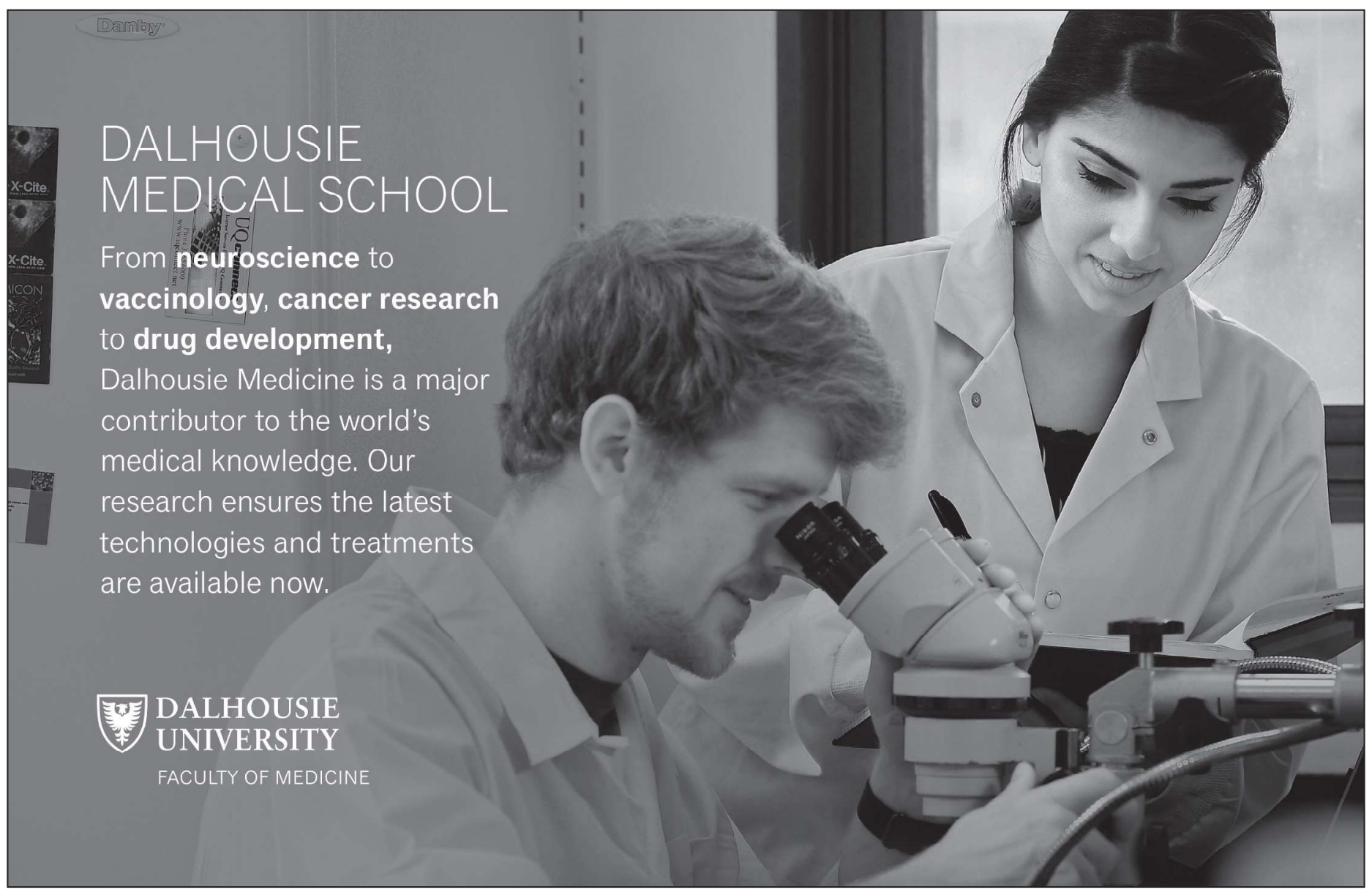

